\title{
REAL OPTIONS THEORY AND STRATEGIC CAPABILITIES DEVELOPMENT
}

\author{
KREMLJAK, Z[vonko] \& HOCEVAR, M[arko]
}

\begin{abstract}
The paper discusses the choice of stochastic process in real options valuation of strategic investments and the main useful tests and theoretical considerations to give support to this task. Also the review of the relevant research literature is given. Development of an organisational system can be described with logic of evolutionary process. It is comprised of variation, selection and retention. In organisational systems, making different decisions acts as a part of variation. Success in correct orientation, which is a consequence of correct decisions, selects the environment of the system. In case of business and production systems this is the market.

Keywords: sustainability, development, capabilities, real options
\end{abstract}

\section{INTRODUCTION}

Different success rate of organisational systems can be explained by different availability of resources. Organisational systems are in their essence heterogeneous and unique, for there a no two alike. Heterogeneity means that organisational systems have different resources or the same resources in an environment of different systems, and are differently effective and productive. Strategic analysis must be turned to resources in a business system and not to the study of relation between products and market. In the second half of the eighties and in the beginning of the nineties authors searched those characteristics of resources which have strategic importance. Resources which explain the success of organisational system are valuable in certain circumstances, rare, inimitable and nonsubstitutable. These characteristics of resources are very important for understanding the successfulness of an organisational system. In the case of business systems one can say that production technology, no matter the level of technological sophistication, cannot be a strategic resource if can be obtained without difficulties on the market. Unique technology which is the outcome of own developmental effort and cannot be bought on market can represent a source of success of a business system. This kind of technology is hard to imitate, because competitive business systems need time to develop similar technology.

\section{REAL OPTIONS}

An option represents an agreement between two parties where the holder of the option has a right, which is not binding, to buy or sell under specified conditions. There are two basic types of options: call options and put options. A call option gives the holder the right to buy stock at a given price before or at a specified date [1].
The price, for which the stock can be purchased, is called exercise price. In advance set final time for exercising of option is called expiration date. European type of call option allows purchase of securities on a specific expiration date, while American call option allows purchase at any given moment up to the specified expiration date. Buying stock represents an exercise of option. The buyer of a call option has to pay for the right to buy. The amount of payment is called price or value of call option. The value of call option represents the difference between the exercise price and current price of the stock.

Methods for evaluating financial options were transferred to evaluating flexibility, in connection with investment projects into physical assets, for example investment into technology, production systems and new product development. This type of option evaluation was named real options [2]. Real options are options, bound to real assets and can be defined as the opportunity to react to changed project circumstances, with developed comprehensive approaches for valuation [3] and [4].

Every change of state poses a question about offered options. Therefore, the knowledge and definition of real options are very important. In literature [1] one can find at least six real options, which are shown in Table 1.

\section{STRATEGIC CAPABILITIES DEVELOPMENT}

Dierickx and Cool pointed out that the strategic resources are those which develop over a longer process [5]. This way they redirected the focus from static resources to dynamic capabilities and paved the way for a new theoretical approach called dynamic capability approach. This approach says that success of an organisational system is explained by the capability to create, change, and redesign the resources with the aim to answer to circumstances that the organisational system faces in its environment. Existence of similar theoretical concepts of production resource theory and dynamic capability approach demand differentiation between resource and capability. In spite of the fact that this difference is not always clear, it can be accurately described. A resource is what an organisational system has. A resource is the assets of an organisational system although these assets are sometimes hard to express in money. Tangible resources in an organisational system are represented by technology. The more this technology is unique incompletely mobile, incompletely imitative 
and incompletely substitutable, the higher its strategic importance. Intangible resources are represented by trademarks, patents, ownership rights, licences and reputation. If resource signifies what an organisational system has, then the capability tells what an organisational system knows. Therefore, capability conceptually represents the knowledge of an organisational system. Dosi et al. claim that the organisational system as a whole has knowledge how to perform activities [6]. The existence of capabilities explains why organisational systems with the same resources can have different success rates. On their basis they will use their resources more effectively.

\begin{tabular}{|ll|}
\hline Type of option & \multicolumn{1}{c|}{ Description } \\
\hline Option to defer & $\begin{array}{l}\text { There is an option that decision on accepting a } \\
\text { project can be deferred to a later time when there } \\
\text { is more information available. This is about } \\
\text { making a compromise between two possible } \\
\text { decisions. To invest immediately, with the aim to } \\
\text { achieve return as soon as possible; or to postpone } \\
\text { the investment to avoid possible loss and to wait } \\
\text { for the uncertainty regarding the future to lessen } \\
\text { and only then, in accordance with the economic } \\
\text { circumstances, decide on investment. }\end{array}$ \\
\hline Option to alter \\
operating scale
\end{tabular}

Tab. 1. Types of real options

The problem of capability management is linked with uncertainty. Structural characteristics represent a notion that capability is also a system. Capability is composed of dispersed knowledge. It is composed of combinations of different knowledgand resources. Capability represents integrated knowledge and this knowledge can be integrated at different levels. Capability is a very complex system. The complexity of this system influences uncertainty, because due to the limited rationality managers never exactly know what the capability of an organisational system is made of. Causal relationships (the term means that we can never with absolute certainty know what are the causes for the competitive advantage of a business system) between structure of capability and environment of a system are never completely clear.

Capability is decidedly defined by process characteristics. Like the knowledge of an individual which is formed in very long cycles and is increasingly a life long learning process, the knowledge of organisational system is developed over a long term process. This means that the capability of organisational system is strategically important, for the competitors cannot simply copy the capability which was created in a long and unique learning process, defied with pathdependency. Uncertainty of developmental capabilities defines the inability of individuals to predict future. The first conjecture is linked to foreseen business opportunities, and the other conjecture is linked to the question if the developed capabilities are the ones that will be in accordance with foreseen business opportunities.

The fact that the process of capability development is uncertain due to complex structure of knowledge in an organisational system and due to long-term development researchers studied the applicability of real options theory to explain the process of capability development. The application of option logic was transferred from finance to real options and to dealing with strategic opportunities. Strategic options arise as an interface between knowledge of an organisational system and opportunities provided by the environment. The existing capabilities enable access to potential opportunities in the future. This kind of opportunities Bowman and Hurry named shadow options [7]. They represent a starting option in option chain (Fig. 1).

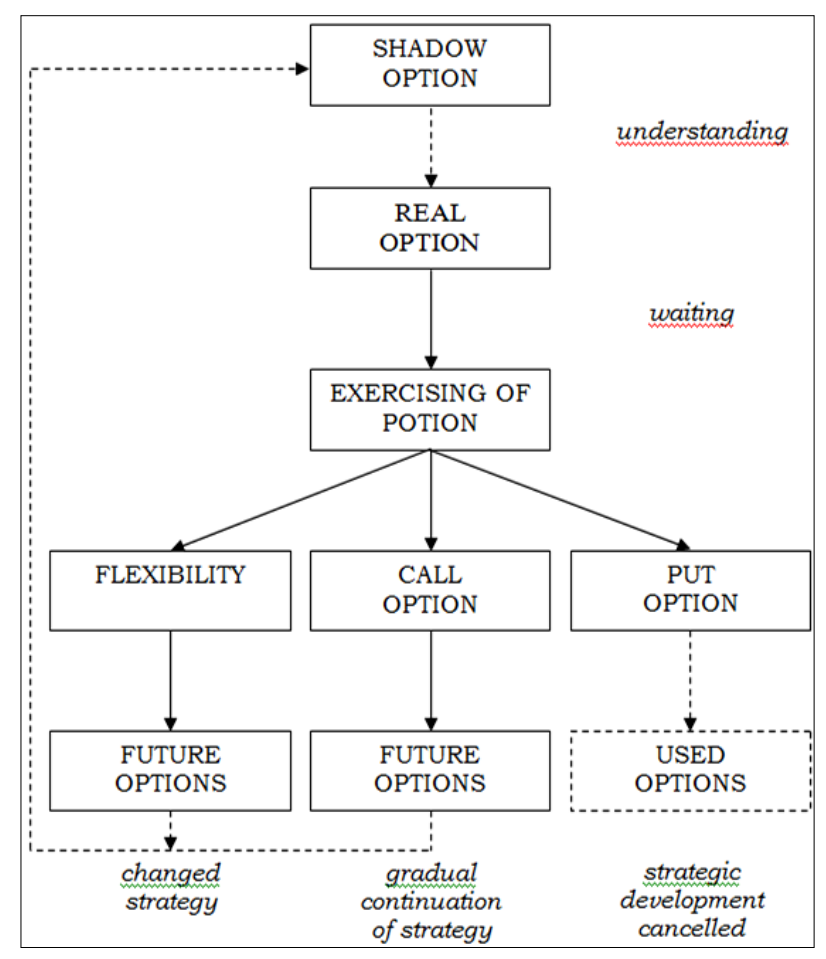

Fig. 1. Option chain 
When business opportunity becomes clear enough and final, it is possible to identify the group of real options which are exercised when the uncertainty diminishes. The capabilities represent the inventory of knowledge which enables the organisational system to use the potential opportunities or remove possible dangers. In other words, by developing capabilities the companies are buying an option for future use of a business opportunity.

Fig. 2 shows the diminishing uncertainty of a capability development project, leading to varying levels of required flexibility at different points in time. The system of resources and their organization has to be adapted. The methods used for development and investment appraisal have to include the possible adaptations of the system and in particular the ability to consider newly arriving information [8].

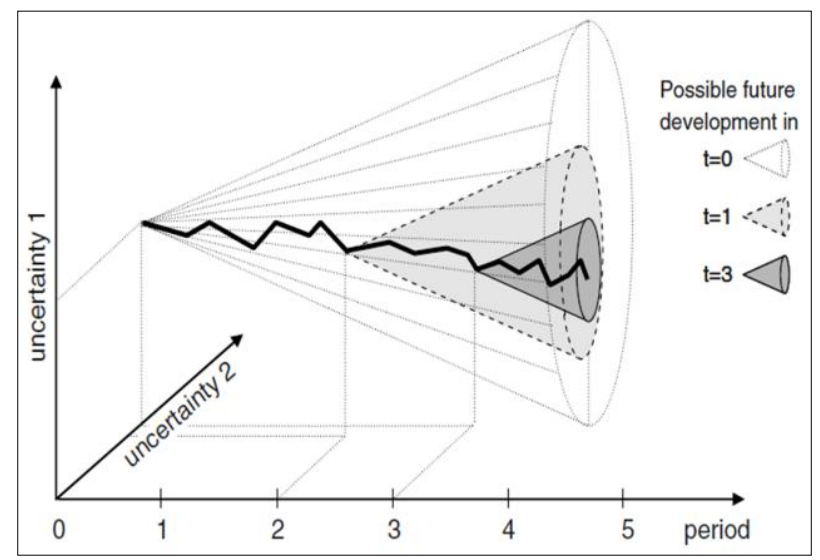

Fig. 2. Development of the uncertainty during the lifecycle of a capability development project

\section{LOGIC OF REAL OPTIONS THEORY AND STRATEGIC CAPABILITY DEVELOPMENT}

The logic of real options is very suitable for understanding capability development. The more the business opportunity is uncertain the more the organisational system will gain, or lose less, if the options are available.

In spite the fact that the logic of real options convincingly explains the capability development, the transfer of mathematical models from financial and investment theory is not without problems. Bowman and Moskowitz used the example of Mercks applied theory of real options for investment analysis for a developmental project and discovered that the results of mathematical problems can be in opposition to strategic analyses [9]. The furthest went Adner and Levinthal in their critique of usefulness of real options theory for capability development [10]. The authors claim that real options theory is applicable only when it is perfectly clear when the project can be abandoned or when to close the option. This should be possible when the system environment and technical agenda can be described with parametric uncertainty. In the event this is a structural uncertainty the organisational systems must use logic of gradual search (Fig. 3).

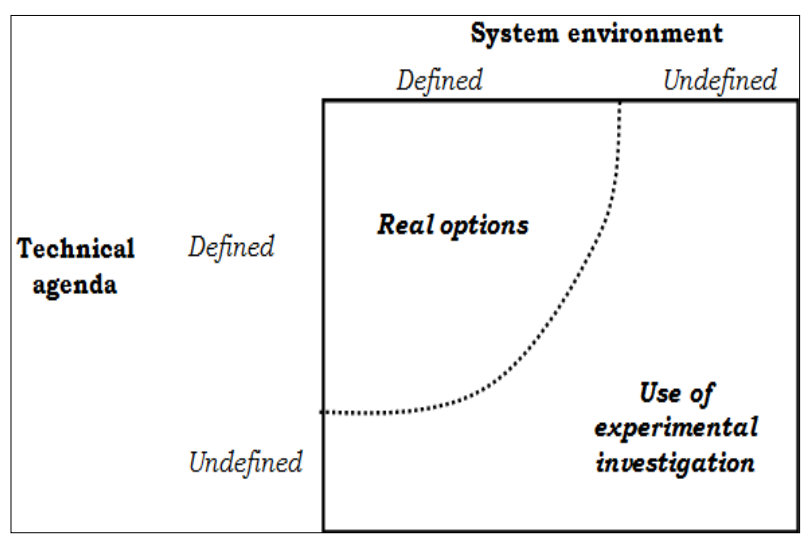

Fig. 3. Boundaries of applicability of real options theory for strategic capability development

Adner and Levithal stress that strategic opportunities and dangers cannot be foreseen with certainty, therefore, the organisational systems will not stop searching for them, which is in opposition with real option logic for it demands that we have clear criteria when to abandon an option. McGrath et al. [11] do not agree with Adner and Levithal. In their critique they answer that it is necessary to differ between investments in production assets which have option characteristics and option logic as heuristics for managing development of strategic capabilities. By directing the development of capabilities with the use of option logic, precisely defined criteria for abandoning the option are not so important. Stressing this criterion would mean that flexibility is linked only to abandoning of option.

Taking into account Bowman and Hurry option chain, this would mean that there would be no strategic flexibility. Organisational system would have two options: to continue developing capabilities or to stop. This removes the meaning of organisational learning. Investing in capability development means to create opportunities for using business opportunities in the future. When these opportunities arise or the uncertainty regarding the existence of opportunities diminishes, organisational system knows more than at the moment the capability development was instigated. If it is able to use this new knowledge for discovering other opportunities that it was unable to predict before it does not mean that development of option logic is not suitable for describing capability development [12] and [13].

Continued innovation in the financial and product markets blurs the distinction between real and financial options, providing better valuations of real assets, and creating more opportunities to manage the risks of strategic investments [2].

The real options approach is a disciplined way of thinking about the consequences of uncertainty. It changes what questions you ask when making strategic investment decisions. There are a lot of solution methods available for calculating option values. These methods use mathematical techniques developed in other fields. With the derivation of options profiles and options priorities, an efficient process of option valuation is possible. Fig. 4 gives an overview of how to derive the overall priority of the existing real options [8]. 


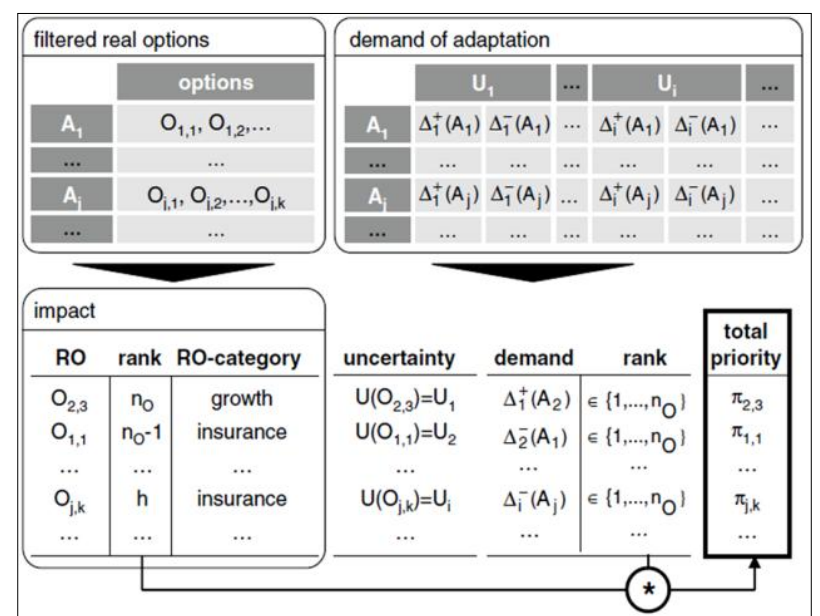

Fig. 4. Derivation of the economic potential of real options [8]

\section{CONCLUSION}

In the last years, the valuation of capability development projects with inherent flexibility in the presence of uncertainty has experienced growing attention. The characteristic elements of financial options, i.e. flexibility, uncertainty and irreversibility, coincide with those of investments and that findings from financial theory may be transferred to calculate the value of real projects. One important feature of real options theory is the consideration of additional information becoming available in the course of the project under observation. In the paper a review of the field and a developed model of strategic capabilities are presented.

The current set of valuation and decision-making tools aren't sufficient for the new business realities:

1. strategic investments with lots of uncertainty and huge capital requirements;

2. projects that must adapt to evolving conditions;

3. complex asset structures through partnerships, licenses, and joint ventures;

4. and the relentless pressure from the financial markets for value-creating strategy.

Scientific literature has shown that transfer of mathematical models from financial environment to the environment of isolated investment projects into production assets is successful. More problems arise when formal mathematical tools are used for complex developmental projects or strategic capability development. With strategic capability development it is almost impossible to precisely define the time left to expiry date. It is difficult to define volatility of an underlying asset. An underlying asset is actually knowledge developed in an organisation, but which is difficult to transform to money value which would be necessary for mathematical treatment. We can say that there is enough evidence in scientific literature that in capability development the mathematical models can be successfully substituted by the use of real options logic. Those who make decisions in organisational systems are advised to use real options logic. Its usefulness will not be increased by mathematical tools, which will reduce complex reality to a few variables, but by development of heuristics which will take into account the complexity of real conditions and at the same time enable decisions based on measurable indices.

The paper helps in achieving the right balance in applications, to use the real options way of thinking (about valuation and strategic decision-making) to shape investments and business strategy.

Real options logic is the right conceptual frame for describing decision making processes in the conditions of high uncertainty. It is difficult to talk about, without additional research, how successful and effective real options logic based approaches would be in solving the problems concerning capability development in very uncertain conditions. The need for managing uncertainty is evident in research and development projects, development of new production technologies, new product development projects, investment in advanced production technology, decisions about moving production and development of production capabilities like flexibility in production, logistics and maintenance and quality management. Our future research plans include the refinement of the selected model parameters.

\section{ACKNOWLEDGEMENT}

The author thanks firm ONE - Telecommunication Services (Telekom Slovenia Group) for the support.

\section{REFERENCES}

[1] Trigeorgis, L. (2002). Real Options - Managerial Flexibility and Strategy in resource Allocation, MIT Press, Cambridge

[2] Kogut, B. \& Kulatilaka, N. (1994). Option thinking and platform investment: investing in opportunity, California Management Review, Vol. 36, No. 2, pp. 52-71

[3] Amico, M.; Asl, F. M.; Pasek, Z. \& Perrone, G.(2006). Real options: an application to RMS investment evaluation. In: Dashchenko, A. I. (Ed.) Reconfigurable manufacturing systems and transformable factories, pp. 675-693, Springer, Berlin

[4] Triantis, A. \& Borison, A. (2001). Real options: state of the practice, Journal of Applied Corporate Finance, Vol. 14, No. 2, pp. $8-24$

[5] Dierickx, I. \& Cool, K. (1989). Asset stock accumulation and sustainability of competitive advantage, Management Science, Vol. 17, No. 1, pp. 121-154

[6] Dosi, G.; Nelson, R. R. \& Winter, S. G. (2000). The Nature and Dynamics of Organizational Capabilities. Oxford University Press, Oxford

[7] Bowman, E. H. \& Hurry, D. (1993). Strategy through the options lens: an integrated view of resource investments and the incremental-choice process. Academy of Management Review, Vol. 18, No. 4, pp. 760-782

[8] Milberg, J. \& Möller, N. (2008). Valuation of changeable production systems, Production Engineering, Vol. 2, No. 4, pp. 417-424

[9] Bowman, E. H. \& Moskowitz, D. (2001). Real options analysis and strategic decision making, Organization Science, Vol. 12, No. 6, pp. $772-777$

[10] Adner, R. \& Levinthal, D. A. (2004). What is not a real option: considering boundaries for the application of real options to business strategy, Academy of Management Review, Vol. 29, No. 1, pp. 74-85

[11] McGrath, R. G.; Ferrier, W. J. \& Mendelow, A. L. (2004). Real options as engines of choice and heterogeneity, Academy of Management Review, Vol. 29, No. 1, pp. 86-101

[12] Kremljak, Z.; Polajnar, A. \& Buchmeister, B. (2005). A heuristic model for the development of production capabilities, Journal of Mechanical Engineering, Vol. 51, No. 11, pp. 674-681

[13] Jaimungal, S. \& Lawryshyn, Y. (2011). Incorporating managerial information into real option valuation. Available from: http://ssrn.com/abstract=1730355. Accessed on: 2012-05-31 